\title{
FILOSOFÍA Y AMISTAD: REFLEXIONES EN TORNO A EPICURO
}

\author{
Juan Carlos Aviani \\ Universidad Católica de Santa Fe
}

\begin{abstract}
"Esto no lo digo yo para los muchos, sino para tí; pues somos el uno para el otro un teatros suficiente".

Epicuro
\end{abstract}

El título del presente trabajo puede resultar extraño o, en el mejor de los casos, sugestivo. I a extrañeza sugiere que tal relación nunca fue pensada o imaginada. Si, por el contrario, resulta ser sugestivo para el lector, será esto índice de que en su espíritu despierta una pregunta ante dicha relación. Tal pregunta puede quizás formularse así: ¿Qué tipo de vínculo puede existir entre la filosofía, entendida como una búsqueda radical y crítica de las verdades que afectan la existencia humana, y la amistad, habitualmente considerada como una particular forma de relación humana fundada en el afecto recíproco entre dos o más personas? La respuesta a esta pregunta se complica cuando la filosofía es considerada una actividad de especialistas, que en y desde el seno de una comunidad académica y científica, abordan problemas referidos directamente a desafíos que le presentan la sociedad y la cultura de la época, como lo pueden ser la necesidad de esclarecimiento epistemológico en el desarrollo de una determinada ciencia o la urgencia por responder desde el 
ámbito de la ética a los graves problemas planteados por la medicina. En tal caso pareciera que la relación entre la filosofía y la amistad sólo puede ser externa y casual, y se daría en el caso de que la común dedicación a la filosofía que puede unir a dos personas sea gratificada por el afecto recíproco. Podría ocurrir también que la amistad se convierta en tema de reflexión y como tal fuera abordado por alguna disciplina filosófica. Sin embargo, podemos con pleno derecho preguntarnos si la relación entre ambos términos no es mucho más profunda y esencial. Dicha pregunta se la dirigimos a Epicuro, no con el afán de historiadores, sino con el propósito de re-pensar con el gran filósofo griego una cuestión que, según creemos, lo merece.

Desde los orígenes mismos del pensamiento griego filosofía y amistad estuvieron estrechamente vinculadas. En efecto, ya los pitagóricos constituían círculos de amigos a lo largo y a lo ancho de toda la Magna Grecia, unión que conformaba la base afectiva y espiritual para la adquisición de la sabiduría. Sin embargo, es quizás en el pensamiento platónico donde tal relación se vuelve más explícita. En la Academia la philia era el vínculo espiritual del grupo, el cual estaba integrado exclusivamente por hombres, pues uno de los objetivos de la Academia era formar los futuros gobernantes que, instruidos en la "noble ciencia de las ideas". pudieran dirigir la ciudad. En ese sentido la amistad que une a los miembros de la Academia tiene como fin provocar la ascensión dialéctica que concluye con la contemplación de las Ideas, y en particular de la Idea de Bien. Como vemos, la philia tiene el valor de intermediario, pues excita y sostiene el impulso erótico que tiene como fin último la sabiduría ( 1 ).

(1) Platón. Banquete, 201 e7-202 b4. 
En Aristóteles, que de hecho participó del clima de amistad que se vivía en la Academia, encontramos un sutil análisis de la cuestión. El autor de la Ética a Nicómaco considera a la amistad una virtud y la estudia en relación con la vida política. En este sentido. la amistad se constituye en el vínculo primario entre los hombres sobre el que se edificara la compleja trama de las relaciones sociales. No obstante. resulta interesante destacar que Aristóteles no reduce a la amistad a una función de socialización primaria, la cual sería luego perfeccionada por las relaciones políticas. En efecto, la philia se constituye también en un cierto télos de la vida social, pues en ella se satisfacen sobradamente aspiraciones esenciales del hombre, como por ejemplo el reconocimiento recíproco de los ciudadanos de la polis independientemente de las relaciones jurídicas. Un célebre pasaje de la Ética a Nicómaco afirma que "cuando los hombres son amigos ninguna necesidad hay de justicia...." (2). Como vemos, la amistad aparece como un vínculo que a la vez sustenta $y$ trasciende las relaciones políticas, contribuyendo decidamente a la búsqueda del bien común. Sin embargo, la philia es sólo una instancia deseable en el camino de los hombres en busca de su perfección, la cual tal vez solo se alcanza en la vida contemplativa, género de vida que Aristóteles considera inaccesible para el común de los mortales.

En lo dicho anteriormente pretendemos haber dejado en claro que, pese a las visibles diferencias, tanto Platón como Aristóteles reflexionaron sobre el fenómeno de la amistad, estableciendo relaciones tanto con la vida política como con la vida teorética o filosófica. Esto evidencia que en el pensamiento de los grandes filósofos griegos la cuestión no era marginal ni anecdótica, sino que por el contrario tenía una relevancia tal que

(2) Aristóteles, Ética a Nicómaco, L VIII, I, 1155 a 25-30. 
justificaba su análisis. En Epicuro, en cambio, ya no será un tema más a tratar. A diferencia de Platón, la philia no será considerada como un medio para alcanzar la sabiduría: filosofía y amistad estarán plenamente identificadas. Para comprender nuestra ultima afirmación, que es la tesis que anima y da sentido a estas páginas, es necesario. en primera instancia retomar el concepto de filosofía presente en Epicuro.

Todas las escuelas filosóficas del período helenístico coinciden en que la filosofía no es una actividad puramente contemplativa. Tanto estoicos como epicúreos, por citar a las escuelas más relevantes de la época, consideran que el fin último del filosofar no es el conocimiento de la realidad, entendido en sentido metafísico, sino la búsqueda del sentido de la vida humana. Dentro de este marco, el problema de la felicidad ocupa un lugar central. En Epicuro, tal concepción de la filosofía es perfectamente clara. En efecto, para nuestro filósofo la misma es una actividad que, al igual que las medicinas al cuerpo, aporta salud al alma, permitiendo asi que el hombre conquiste la dicha buscada: "Ína es la palabra de aquel filósofo que no remedia ninguna dolencia del hombre. Pues asi como ningún heneficio hay de la medicina que no expulsa las enfermedades del cuerpo, tampoco la hay de la filosofia si no expulsa la dolencia del alma" (3). Al respecto leemos también: "...nuestra única ocupación ha de ser la de curación de nuestras almas" (4). La filosofía tiene pues una función salvadora, ya que debe liberar al hombre, por medio de la reflexión. de todo aquello que le impide ser feliz. No debemos engañarnos, sin embargo, con el alcance de este ideal salvífico. El afán liberador tiene como único destinatario al individuo que decide compartir la senda filosófica

(3) Epicuro, Frag. 221 Usener $=247$ Arrighetti, en Epicuro, "Opere", A Cura di Graziano Arrighetti.

(4) Epicuro, Gnomologio I'aticuno, LXIV; en Arrighetti, Op.cit., p. 152. 
junto a su maestro. Bien lejos está del ánimo de Epicuro el deseo utópico de reformar la sociedad. Le era indiferente la popularidad de su doctrina y la estima social que esta le pudiera deparar: "Jamás pretendí agradar a la muchedumbre porque lo que a ella le complace, yo lo desconozco, y lo que yo sé, está bien lejos de su entendimiento" (5). La filosofía se presenta, pues, como una actividad necesaria para la vida, ya que su constante ejercicio permite al que se entrega a ella edificar una existencia plenamente humana: "El joven no debe diferir el estudio de la filosofia. ni el anciano hastiarse de ese estudio. Pues nunca es demasiado temprano ni demasiado tarde para ocuparse en la salud del alma. Y decir que la hora de consagrarse a la filosofia no ha llegado aún o ya ha pasado es como decir que la hora de ser feliz no ha llegado todavía o ha pasado ya..." (6).

Filosofía y felicidad. Filosofía y salud. Términos que en muchos pasajes de la obra de Epicuro aparecen indisolublemente asociados. I a necesidad de filosofar se torna imperiosa, pues sólo así podrá el hombre liberarse de todo aquello que lo aqueja y lo atormenta, a la par que lo aleja de la dicha. La filosofía deviene entonces terapia. curación por medio de la palabra. Ahora bien. resulta necesario preguntarse por todo aquello que turba el alma del hombre $y$ le impide alcanzar la tan ansiada felicidad. Para poder responder a este interrogante debemos remontarnos al punto de partida de la filosofía epicúrea.

En el origen de todos nuestros males, de todas nuestras desdichas, se encuentran para Epicuro, el temor y el deseo. Debemos pues analizar estas realidades que acosan al hombre, a punto tal que le impiden iniciar el camino de la liberación personal. Los deseos ilimitados aparecen a los ojos de Epicuro

(5) Epicuro. Frag. 187 Usener $=131$ Arrighetti, ()p.cit., p. 475.

(6) Epicuro. Epistola III, 122: en Arrighetti, Op.cit., p. 106. 
como una de las causas fundamentales de la infelicidad de los hombres, pues siempre media un abismo entre las aspiraciones que se tienen y lo que efectivamente se obtiene de la vida. Para evitar esta situación es preciso, pues, examinar detenidamente los deseos y distinguir aquellos que corresponden a exigencias naturales o esenciales de aquellos otros surgidos en el devenir histórico de la humanidad.

Los deseos naturales son, en la óptica de Epicuro, relativamente fáciles de satisfacer y conducen directamente al hombre a estados placenteros. Acuden en su auxilio en este caso bienes simples, que prudentemente administrados, colman nuestras necesidades básicas. Epicuro se refiere a ellos con la expresión "gritos de la carne": "Los gritos de la carne son: no tener hambre, no tener sed, no tener frio. Quien goza de este estado y tiene la esperanza de gozar de él, puede rivalizar en felicidad con el propio Zeus" (7). Resulta sumamente curioso que en el texto citado no incluya Epicuro al deseo sexual dentro de lo que denomina "gritos de la carne". expresión que por otro lado es particularmente fuerte. En efecto. siempre se asoció el epicureísmo con un hedonismo desmesurado y como tal se lo condenó. incluso en sus mismos orígenes. Sin embargo, en muchos pasajes de la obra de Epicuro queda evidenciada una actitud sumamente cauta y moderada al respecto, al punto tal que en una carta destinada a un joven acosado por violentos deseos carnales, y luego de evitar toda censura, concluye "...los placeres del amor nunca han sido de provecho para nadie, y mucho es ya cuando no dañan" (8). La sabiduría epicúrea es, pues, clara: satisfacer nuestros deseos naturales evitando los excesos. No se trata, sin embargo, de una actitud ascética ante la vida: "Tenemos por un gran bien la independencia respecto de

(7) Epicuro, Gn.V., XXXIII; en Arrighetti, Op.cit., p. 146.

(8) Epicuro, Gn.V., L I: en Arrighetti. Op.cit., p. 151. 
los deseos, pero no en la intención de vivir siempre de poco. sino para que, si falta la ahundancia, sepamos contentarnos con ese poc'()" (9). Como podemos apreciar. la prudencia y la mesura tienen aquí un rol de suma importancia, y en este punto resulta Epicuro, sin lugar a dudas, heredero de la tradición aristotélica.

Los deseos a los que hacíamos referencia no son, sin embargo, los únicos. Ya habíamos dicho que, para Epicuro, hay otra clase de deseos nacidos al calor de la vida social: son los deseos adventicios. El calificativo de adventicios indica cierto carácter de artificialidad, lo cual no debe extrañarnos si tenemos en cuenta que para nuestro filósofo tales deseos no responden a exigencias naturales. En efecto, surgidos en el seno de una sociedad que alaba y recompensa al triunfador. y en este punto se revela Epicuro como un crítico de la moral tradicional griega de cuño homérico, los deseos de poderío, de riqueza y de honores constituyen un serio obstáculo para la conquista de la felicidad, pues ponen a quien los persigue bajo la dependencia de los otros hombres y de la fortuna. Resulta entonces condición necesaria para liberarse de ellos la renuncia a la vida pública, pues los trastornos que este género de vida acarrea son incontables. Un fragmento que se ha hecho célebre lo expresa con toda claridad: "Vive de lo oculto" (10). Y en otro pasaje podemos leer: "La turbación del alma no se aquieta, no sea crea la verdadera alegría, ni por la posesión de los mayores bienes, ni por el honor y la consideración a los ojos de la multitud...."(11). En este punto la ética epicúrea se revela como crítica de la tradición cultural griega y de su correspondiente sistematización filosófica, al afirmar la necesidad de renunciar a participar en la vida de la polis. Los textos de Epicuro que se

(9) Epicuro, Ep. III, 130-131; en Arrighetti, Op.cit., p. 112.

(1) Ëpicuro, Frag. 551 Us.; = Arrighetti n 144, p. 490.

(11) Epicuro, Gin.l.. LXXXI: en Arrighetti, Op.cit.. p. 156. 
ocupan de la cuestión son numerosos y en todos ellos queda en claro su postura: "Hay que liberarse de la cárcel de los intereses culturales y de la política" (12).

Limitados los deseos naturales y eliminados los culturales por medio de la renuncia a la acción, resta solo alejar todo temor del alma humana. Efectivamente, para Epicuro el hombre vive acosado por el temor a los dioses, al sufrimiento y a la muerte. Y para poder desterrar estos temores que impiden una existencia feliz, es menester recurrir al conocimiento de la naturaleza. Tal saber, contenido en la Física, no es en absoluto un fin en si mismo, sino sólo un medio para adquirir seguridad frente a realidades aparentemente amenazadoras. Muchos son los textos de Epicuro que hacen referencia a la cuestión: "Si nada nos perturbaran los recelos ante los fenómenos celestes y el temor de que la muerte sea algo para nosotros, y además el desconocer los límites de los dolores y de los deseos, no necesitariamos de la investigación de la naturaleza" (13). El estudio de la naturaleza, que Epicuro denomina "physiologia", es por lo tanto necesario para la vida. Gracias a él sabemos que "Los dioses no son de temer: ningún riesgo se corre con la muerte; el bien es fácil de procurar; el mal fácil de soportar con fortaleza" (14). En efecto, los dioses no son de temer pues no se ocupan en absoluto de los asuntos humanos. En la teología de Epicuro la divinidad lleva una existencia separada y perfecta, alejada de toda preocupación mundana. En lo que respecta a la muerte, dos motivos permiten al hombre adquirir seguridad frente a ella: por un lado, y como consecuencia de su concepción materialista de la realidad. Epicuro afirma que toda conciencia desaparece en el

(12) Epicuro, Gn.V., LVIII; en Arrighetti, Op.cit., p. 152.

(13) Epicuro, Máximas Capitales, 11: en Arrighetti, Op.cit., p. 124.

(14) Filodemo, Contra los Estoicos, Pap. Hercul., 1005, en A.J.Festugiere, Epicuro y sus Dioses, Buenos Aires, Eudeba, 1979, p. 26. 
momento en que la vida nos abandona, y por lo mismo toda capacidad para sufrir. Por otro lado, y por lo dicho anteriormente, no debe el hombre esperar ni juicios ni castigos póstumos de los dioses, pues éstos son, por asi decirlo, indiferentes al destino de los mortales.

La ultimo cita de Epicuro es clave para conocer su pensamiento. Por nuestra parte, sólo deseamos dejar constancia del valor instrumental que posee el conocimiento de la realidad. En efecto, éste no constituye la sabiduría misma, sino que sólo prepara el terreno para ella, suprimiendo los obstáculos que le impiden al hombre alcanzar la felicidad. La physiologia, que elimina las razones para temer es, pues, una propedéutica.

Libre de los deseos que acosan al común de los hombres y adquirida una firme confianza respecto de los dioses, la muerte y el sufrimiento, el hombre que ha iniciado el camino que conduce a la felicidad, llega a la cicurcixia, a la tan ansiada ausencia de turbación. Ahora bien, la citaraxia representa como tal un estado negativo y no es posible pensar que llene de un contenido positivo la noción de felicidad. Es, podríamos decir, un medio, la condición indispensable para llevar una vida feliz, pues nadie que sufre en la carne o en el espíritu puede considerarse dichosos. Será necesario, entonces, buscar algo más, algo que colme el alma humana y le permita alcanzar una dicha que en cierto modo rivalice con la de los dioses. Y Epicuro lo encuentra en la amistad.

Ya habíamos indicado que la amistad, como sentimiento y como virtud, había sido calurosamente elogiada por la filosofía antigua. Pero en las consideraciones que se hacían sobre ella siempre aparecía vinculada, en mayor o menor medida, a la vida política. Y esto era así pues en el seno de la polis se realizaba en plenitud la vida del individuo y la esfera de 
la vida privada se integraba sin mayores dificultades a ella. Muy otra es, sin embargo, la situación en los años en que Epicuro desarrolla su pensamiento. Un pasaje de la bella obra de Festugiere sobre nuestro filósofo lo expresa claramente: "El fin del siglo IV es un momento de gran desconcierto moral. Por una parte, habiendo perdido la ciudad el libre ejercicio de su autonomía, el marco cívico, del que ha podido decirse que presentaba la rigidez de una iglesia, tiene menos fuerza para mantener, dirigir $y$, de ser necesario, fortificar al individuo; además, el vínculo familiar ya no es tan sólido en Grecia como lo era antes. Por otra parte, esos marcos se han debilitado en un momento en que el análisis, llevado muy a fondo ya, de todos los matices del pensar y el sentir había conducido a una civilización muy refinada que no podía sino tornar la conciencia más delicada y por lo tanto más inquieta. El hombre ya no está sostenido. se siente solo y es presa de escrúpulos, remordimientos, turbaciones del ánimo, que experimenta ahora con más acuidad que antes. Llega, pues, la hora en que se tiene necesidad de dirección moral, en que el sabio será, esencialmente, un director de almas". (15)

$\mathrm{Al}$ respecto resulta interesante destacar que varias de las Sentencias Capitales y un gran número de las máximas dispersas en los fragmentos han sido extraídas de cartas de dirección espiritual. Y en realidad este hecho no es casual: Epicuro mismo entiende que la misión del sabio, como ya lo habíamos visto, es la de curar el alma enferma del hombre. Ahora bien, como acertadamente lo destaca Festugiere, nuestro filósofo es aún demasiado griego para pensar que la liberación del alma de los males que la acosan puede efectuarse en soledad, al margen de todo contacto con otros hombres: resulta imperioso pues consti-

(15) A.J. Festugiere, Op.cit., p. 29. 
tuir una sociedad ideal de amigos nucleados entorno a un maestro que sea, fundamentalmente, un director moral. Y en este sentido es que la sabiduría será, antes que nada, vida espiritual, siendo el ejercicio de la sabiduría la práctica de esa vida.

Son numerosísimos los fragmentos de cartas, fundamentalmente dirigidas a adolescentes que ilustran adecuadamente este ejercicio de dirección moral. En todas ellas se ponen de manifiesto las líneas centrales de su doctrina ética, doctrina a la que hicimos referencia en páginas anteriores. No obstante, el fin último de las mismas no es teórico, sino práctico: pretenden orientar, servir de estímulo, reconfortar sobre todo a los jóvenes y a su círculo de amigos, en un momento histórico de gran crisis y desorientación. Al respecto, Epicuro sabía perfectamente que una de las necesidades más profundas que posee el hombre, y más aún en una situación tal, es la de encontrar un guía cuya palabra y ejemplo valgan por ley: "La veneración por un sabio es un gran bien para los que veneran", expresa un texto que ha llegado hasta nosotros (16). Y en el mismo sentido comparaba al sabio con un dios en medio de los hombres: "...más vivirás como un dios entre los hombres" (17). Muchos siglos después, el mismo Lucrecio se hará eco de este pensamiento acerca de la importancia del sabio, refiriendo sus palabras a Epicuro: "Fue un dios. Si, Memio, sólo un dios ha podido hallar por vez primera ese camino de vida que se llama hoy Sabidurí" (18).

Sin lugar a dudas, estamos ya en condiciones de entender cabalmente lo que representaba la amistad para la filosofía epicúrea y qué relación tenía con la Sabiduría. Vínculo fundamental entre el maestro y sus discípulos y de éstos entre sí,

(16) Epicuro, Gn.V., XXXII; en Arrighetti, Op.cit., p. 146.

(17) Epicuro, Ep.III, 135: en Arrighetti, Op.cit., p.116.

(18) Lucrecio, De rerum natura, V, 8. 
la amistad se convierte en el seguro refugio desde el cual sobrellevar con fortaleza las vicisitudes de una época cargada de turbulencias y los golpes que la inconstante fortuna pudiera asestar a la frágil naturaleza humana. La clara doctrina del Maestro, expuesta con precisión y asegurada de una vez y para siempre, suministraba todas las respuestas necesarias para llevar una vida plenamente humana y feliz. Solo restaba la tarea de comprenderla en todos y cada uno de sus detalles, siendo ésta la ocupación central de sus discípulos. Tal labor, emprendida en comunidad, colocaba a la amistad en un primer plano absoluto, pues no era ésta un estímulo en el curso de las investigaciones, sino la preocupación fundamental de los discípulos, que ya tenían en sus manos, por así decirlo, el tesoro de la verdad. Se trataba ahora de ser feliz, y tal felicidad se alcanzaba gracias al reconocimiento recíproco, a la mutua confianza y a la libre apertura de los espíritus, que en la solidez del vínculo amistoso, conquistaban la tan ansiada paz del alma. En este sentido es que la amistad es el fruto más precioso que nos entrega la sabiduría, pues consuma el camino de liberación emprendido por el filósofo, a tal punto que la misma muerte será por ella iluminada: "He aquí el día más bello de mi vida: es el último. Mis dolores de vejiga y mis cólicos continúan, siempre extremos, sin amenguar su violencia. Pero a todos ellos opongo la alegría del alma, al recordar nuestras antiguas pláticas. Tú que desde la adolescencia has sido fiel tanto a mí como a la filosofia, vela con solicitud por los hijos de Metrodoro" (19).

(19) Epicuro, Frag. 138 Usener; = en Arrighetti, Op.cit., p. 427 